\title{
Identification of heterotic cross combinations for various agromorphological and some quality traits in bread wheat (Triticum aestivum L.)
}

\author{
Sandeep Kumar ${ }^{1}$, Pradeep Kumar ${ }^{2 *}$ Vichitra Kumar Arya ${ }^{2}$, Ravi Kumar ${ }^{1}$, Gaurav \\ Kamboj $^{1}$ and S. A. Kerkhi ${ }^{1}$ \\ ${ }^{1}$ Sardar Vallabhbhai Patel University of Agriculture and Technology, Meerut-250110 (UP), INDIA \\ ${ }^{2}$ Indian Institute of Wheat and Barley Research, Karnal-132001 (Haryana), INDIA \\ *Corresponding author. E-mail: pradeeptaliyan231@gmail.com
}

Received: February 16, 2017; Revised received: July 24, 2017; Accepted: September 18, 2017

\begin{abstract}
A study was conducted to identify the best heterotic cross for various agromorphological and some quality traits involving 10 parents and their $45 \mathrm{~F}_{1} \mathrm{~s}$ excluding reciprocals during 2012-13 and 2013-14. The higher magnitude of heterosis for all the agromorphological and quality traits was not expressed in a single cross combination. It varied from cross to cross due to diverse genetic background of their parents. The highest heterobeltiosis $(35.68 \%$, $11.11 \%, 11.44 \%)$, average heterosis $(38.97 \%, 9.13 \%, 10.26 \%)$ and standard heterosis $(31.09 \%, 7.84 \%, 10.41 \%)$ for grain yield, spikelets per spike and grains per spike respectively, was showed by HD $3095 \times$ RAJ 4246 and this cross also showed highly significant (at $<1 \%$ level of significant) heterosis for biological yield, flag leaf area, spike length and productive tillers. Whereas PBW $435 \times$ RAJ 4246 were common for gluten content $(8.52 \%$ and $7.72 \%)$, grain yield $(33.11 \%$ and $33.64 \%)$, productive tillers $(16.15 \%$ and $13.53 \%)$ and biological yield $(36.27 \%$ and $21.98 \%)$ which showed superior average heterosis and heterobeltiosis respectively, therefore, these crosses may be exploited in a national hybrid wheat breeding programme may offer genetic improvement in breeding for higher grain yield, agromorphological and quality traits in bread wheat. The presence of high heterosis for yield contributing components is not only for developing hybrids through exploitation of heterosis but also helps to produce transgressive segregants for developing of superior homozygous lines.
\end{abstract}

Keywords: Agromorphological and quality traits, Bread wheat, Diallel, Heterosis, Grain yield

\section{INTRODUCTION}

The use of heterosis for getting high yield with improved quality has been largely used in cross pollinated crops but now in self pollinated crops evidences are available to confirm the potential use of heterosis. Wheat (Triticum aestivum L.) is a highly self pollinated crops, scope for the exploitation of hybrid vigour depends on the direction and magnitude of heterosis, biological feasibility of crop and nature of gene action. It is grown over 30.23 million hectares area with total production amounting to 93.50 million tonnes (201516) and average productivity of 2.9 tonnes/ha. At global level, India ranks second largest wheat producing nation after China. India's share in world wheat area is about $12.5 \%$, whereas it occupies $13.43 \%$ in total world wheat production (Anonymous 2016). Wheat production can be enhanced through the development of new cultivars having wide genetic base and better performance under various agro-climatic conditions. Wheat is the leading source of vegetable protein in human food, having higher protein content than either maize (corn), rice or the other major cereals, to assume increasingly greater importance as a source of protein for much of the world's increasing population. Hetero- sis breeding is one of the important tools to take a quantum jump in production and productivity under different agro-climatic conditions. Longin et al. (2012) reported that yield due to exploitation of heterosis can be improved ranged from 3.5 to $15 \%$ in wheat crop. Estimation of heterosis in wheat crop have also been reported by Singh et al. (2012), Singh et al. (2014), Kumar and Kerkhi (2014), Kumar et al. (2015) and Kumar et al. (2016) for grain yield, plant height, productive tillers, gluten content, days to maturity, days to flowering and several other agromorphological traits. The future scope of hybrid technology in wheat depends on the male sterility systems, floral biology, level of combining ability and heterosis and its exploitation of economic level that may be used in breaking yield barriers and enhancing the productivity in the major wheat growing belt of the country (Singh et al. 2010). Therefore the main objective of the present study was to examine the heterosis over mid parent (average heterosis), better parents (heterobeltiosis) and standard parent (standard heterosis) for grain yield, agromorphological and quality traits and also to identify the heterotic combination which may be further exploited through heterosis breeding programme. 


\section{MATERIALS AND METHODS}

The base material consisted 10 diverse genotypes of bread wheat (PBW 435, HD 2967, MP 3336, MP 4010, DBW 90, HD 2824, HD 3095, RAJ 4246, NW 5038 and HD 2733) was planted at Crop Research Centre, Sardar Vallabhbhai Patel University of Agriculture and Technology, Meerut during rabi 20122013 for attempting crossing in a 10x10 diallel fashion excluding reciprocals. In the next crop season (i.e.rabi 2013-2014), experimental material consisted a total 55 genotypes (10 parents and their $45 \mathrm{~F}_{1} \mathrm{~s}$ ) was sown in a randomized block design with three replications. Seeds of each of the parental lines and also $F_{1}$ s were dibbled in two row plot of 2 meter length maintaining spacing of $10 \mathrm{~cm}$ among plants within a row and $23 \mathrm{~cm}$ between rows. All the standard agronomical practices were followed to raise normal crop. Observations were recorded on five randomly selected plants in each replication for days to $50 \%$ flowering, days to maturity, plant height $(\mathrm{cm})$, number of productive tillers per plant, flag leaf area $\left(\mathrm{cm}^{2}\right)$, spike length $(\mathrm{cm})$, number of spikelets per spike, number of grains per spike, biological yield per plant $(\mathrm{g})$, grain yield per plant $(\mathrm{g})$, harvest index (\%) and gluten content (\%). The mean values of parents and $F_{1 s}$ crosses for these traits were used to estimates the heterosis over better parent (heterobeltiosis), over mid parent (average heterosis) and over standard parent (standard heterosis). The magnitude of heterosis was estimated by commonly used statistical software (INDOSTAT 7.5). Analysis of variance was done as per the method suggested by Panse and Sukhatme, (1967). The percent increase or decrease of $F_{1}$ hybrids over better parent was calculated by using the formulae of Fonseca and Patterson (1968).

Heterosis $(\%)=\frac{\text { F1-PM }}{\text { PMI }} \times 100$

$\mathrm{F}_{1}=$ Mean performance of $\mathrm{F}_{1}$ hybrid; $\mathrm{PM}=$ Mean performance of parent.

\section{RESULTS AND DISCUSSION}

The name of the parents, their pedigree, origin, area of adoption and production condition is presented in (Table 1).In the present study, analysis of variance
(Table 2) for treatments, parents, hybrids and parents $v s$. hybrids showed highly significant (at $<1 \%$ level of significant) for all the traits except gluten content in treatment; productive tillers and gluten content in parents; productive tillers, harvest index and gluten content in hybrids; days to $50 \%$ flowering, days to maturity, spike length, harvest index and gluten content in parents vs. hybrids, indicated that sufficient variability was existed in the present set of material and further genetic analysis would be meaningful. Estimated value of heterosis showed that the degree and direction of heterosis varied not from trait to trait but also in cross to cross. Singh et al. (2004) stated that the superiority of hybrids particularly over high parent is more useful for commercial exploitation of heterosis also indicated that parental combinations capable of producing the highest level of transgressive segregants. The estimates of heterobeltiosis, average heterosis and standard heterosis with the check HD 2967 were present in (Table 3).

Heterobeltiosis for days to $50 \%$ flowering was ranged from $-3.46 \%$ (PBW $435 \times$ HD 2733) to $1.17 \%$ (DBW $90 \times$ NW 5038). The cross with highest negative and significant heterobeltiosis was $-3.46 \%$ (PBW $435 \mathrm{x}$ HD 2733) whereas cross HD 2967 x DBW 90 showed highest average heterosis for days to $50 \%$ flowering. For days to maturity, heterobeltiosis ranged from -1.46 \% (HD $2824 \times$ HD 2733) to $0.49 \%$ (DBW $90 \times$ Raj 4246). The crosses which showed highest significant and negative heterobeltiosis were $-1.46 \%$ (HD $2824 \mathrm{x}$ HD 2733) and $-1.46 \%$ (NW $5038 \times$ HD 2733). The negative and significant standard heterosis was also reported by Singh et al. (2012) in cross HD 2285 x K $7903(-18.87 \%)$ for days to flowering and in K $9423 \mathrm{x}$ $\mathrm{K} 7903(-31.07 \%)$ for days to maturity and they reported standard heterosis in 17 crosses range from -18.87 to 4.21 percent in wheat crop. Singh et al. (2014) reported heterobeltiotic value range from -7.64 to 29.30 percent for days to flowering and range from -7.93 to 16.13 percent for days to maturity whereas standard heterotic value range from -29.55 to 5.82 percent for days to flowering and range from -26.29 to 5.37 percent for days to maturity in wheat. The heterobeltiotic value range from -8.10 to 7.77 percent for days to

Table 1. The pedigree and origin of the parental lines used in crossing programme.

\begin{tabular}{|c|c|c|c|c|}
\hline Parents & Parentage/ pedigree & $\begin{array}{l}\text { Area of } \\
\text { Adoption }\end{array}$ & $\begin{array}{l}\begin{array}{l}\text { Production } \\
\text { condition }\end{array} \\
\end{array}$ & Origin \\
\hline PBW-435 & HD 2160/CALIDAD & & & Ludhiana \\
\hline HD-2967 & ALD/COC//URES/HD2160M/HD2278 & NWPZ/NEPZ & TS, IR & New Delhi \\
\hline MP-3336 & HD2402/4W173 & $\mathrm{CZ}$ & LS, IR & Jabalpur \\
\hline MP-4010 & ANGOSTURA88 & $\mathrm{CZ}$ & LS, IR & Jabalpur \\
\hline DBW-90 & HUW468/WH 730 & NWPZ & LS, IR & Karnal \\
\hline HD-2824 & PTO-1/CNO79/PRL/GAA/3/HD 1951 & NEPZ & TS, IR & New Delhi \\
\hline HD-3095 & CPAN300/WR426//HW2007//HD2851 & & & New Delhi \\
\hline RAJ 4246 & RAJ 3765/WR544 & & & Durgapura \\
\hline NW-5038 & WAXWING*2/VIVITSI & & & Kumarganj \\
\hline HD-2733 & ATTILA/3/TUI/CARC//CHENICHTO/4/ATTILA & NWPZ/NEPZ & LS/VLS, IR & New Delhi \\
\hline
\end{tabular}




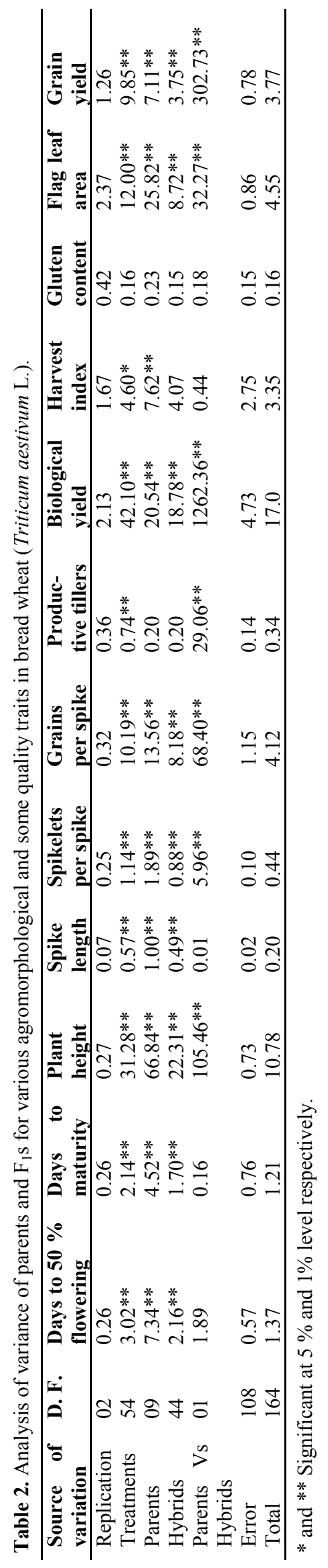

flowering and range from -3.55 to 4.08 percent for days to maturity was also reported by Kumar et al. (2015). A range of heterobeltiosis for plant height was from $-3.87 \%$ (MP $4010 \times$ HD 2733) to $2.37 \%(\mathrm{PBW}$ $435 \times$ HD 2967). The cross MP 4010 X HD 2733 ($3.87 \%$ ) and DBW $90 \times$ HD $2733(-4.63 \%)$ showed highest negative and significant heterobeltiosis and standard heterosis respectively for plant height. The negative and significant standard heterosis $(-4.66 \%)$ and average heterosis $(-20.85 \%)$ was also reported by Singh et al. (2012) in cross HUW x K 2021 (-4.66\%) for plant height in wheat. Heterosis in both positive and negative direction for plant height was reported by Singh et al. (2012) and they observed standard heterotic value in 4 crosses range from -4.66 to 48.13 percent and average heterosis value in 12 crosses range from 20.85 to 39.91 percent. Singh et al. (2014) reported heterobeltiotic value range from -17.11 to 16.82 percent and standard heterosis value range from -25.17 to 2.63 percent for plant height whereas Kumar and maloo (2012) reported relative heterotic value range from -14.80 to 9.29 percent for plant height in wheat. The heterobeltiotic value range from -18.55 (K 9423 x UNNAT HALNA) to 9.53 percent (PBW $373 \times$ UP 2425) for plant height was also reported by Kumar et al. (2015). Same pattern of positive and negative heterosis for plant height in wheat crop were also earlier reported by Kumar and Kerkhi (2014) and Kumar et al. (2016). Negative heterosis for days to flowering, days to maturity and plant height is generally important for the development of short duration and dwarf type of wheat genotypes.

The ranged of heterobeltiosis for flag leaf area varied from $-22.49 \%$ (HD $2824 \times$ Raj 4246) to $17.71 \%$ (MP $3336 \times$ NW 5038). The cross MP 3336 x NW 5038 showed highest heterobeltiosis $(17.71 \%)$ and standard heterosis (33.36\%) whereas cross HD 2967 x HD 3095 showed highest average heterosis $(20.67 \%)$ for flag leaf area. The positive and significant average heterosis range from -51.98 to 53.48 percent and heterobeltiosis value range from 6.60 to 39.63 percent was reported by Kumar and Maloo (2012) for flag leaf area and also identify two best crosses namely DBW 16 x UP 2338 and DBW 17 x UP 2338 in wheat crop. The heterobeltiotic value range from -37.73 (PBW 373 x K 7903 ) to 28.62 percent (K $9423 \times$ NW 1014) for flag leaf area was also reported by Kumar et al. (2015). Same pattern of positive and negative heterosis for flag leaf area in wheat crop were also earlier reported by Kumar and Kerkhi (2014) and Kumar et al. (2016). Flag leaf is responsible for more than $70 \%$ photosynthesis and thus is important for grain filling. Positive heterosis for flag leaf area can be exploited as a beneficial trait as it increases the chance of getting healthy and good quality grain and significant in photosynthetic activity.

The magnitude of heterobeltiosis for productive tillers 


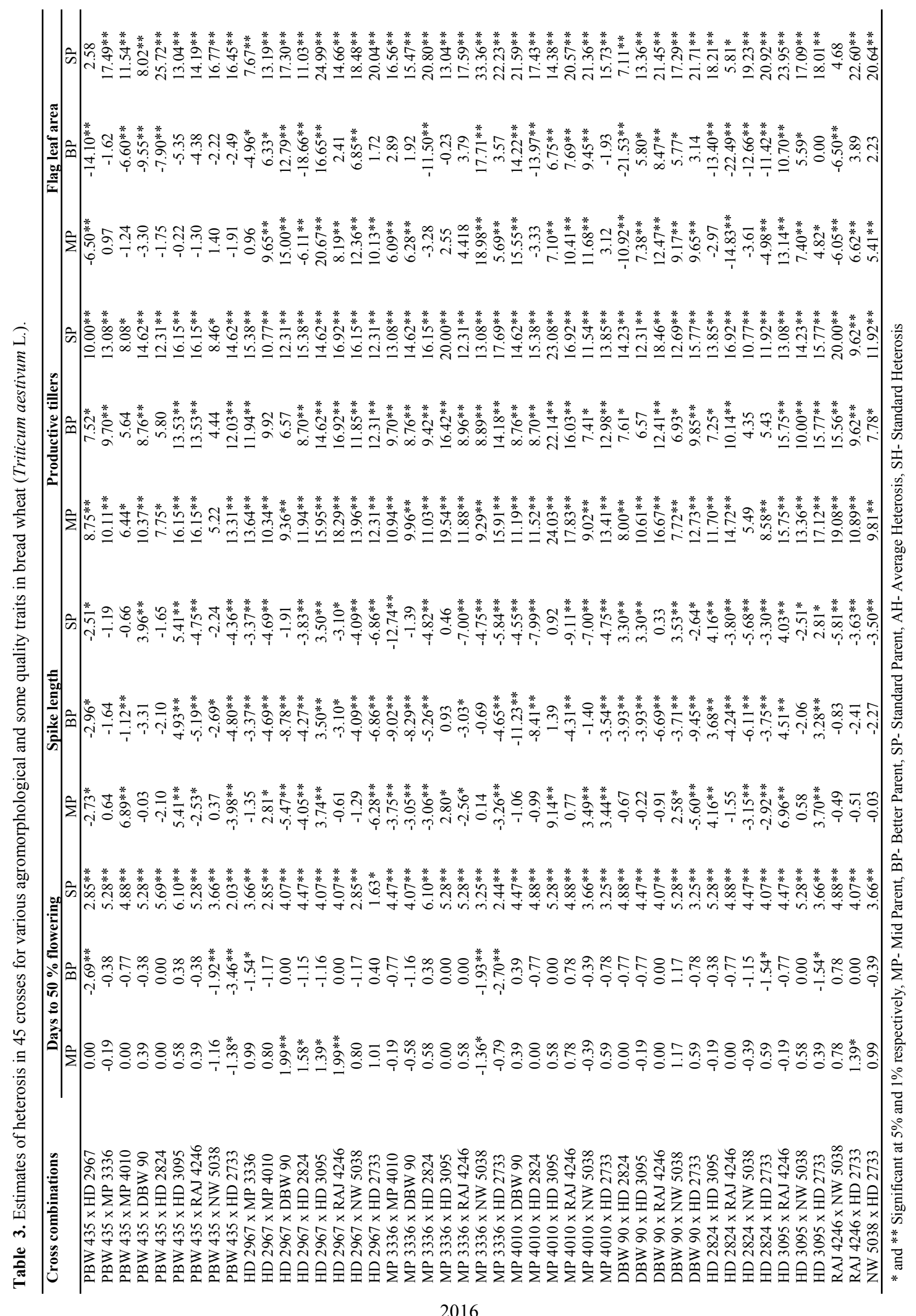




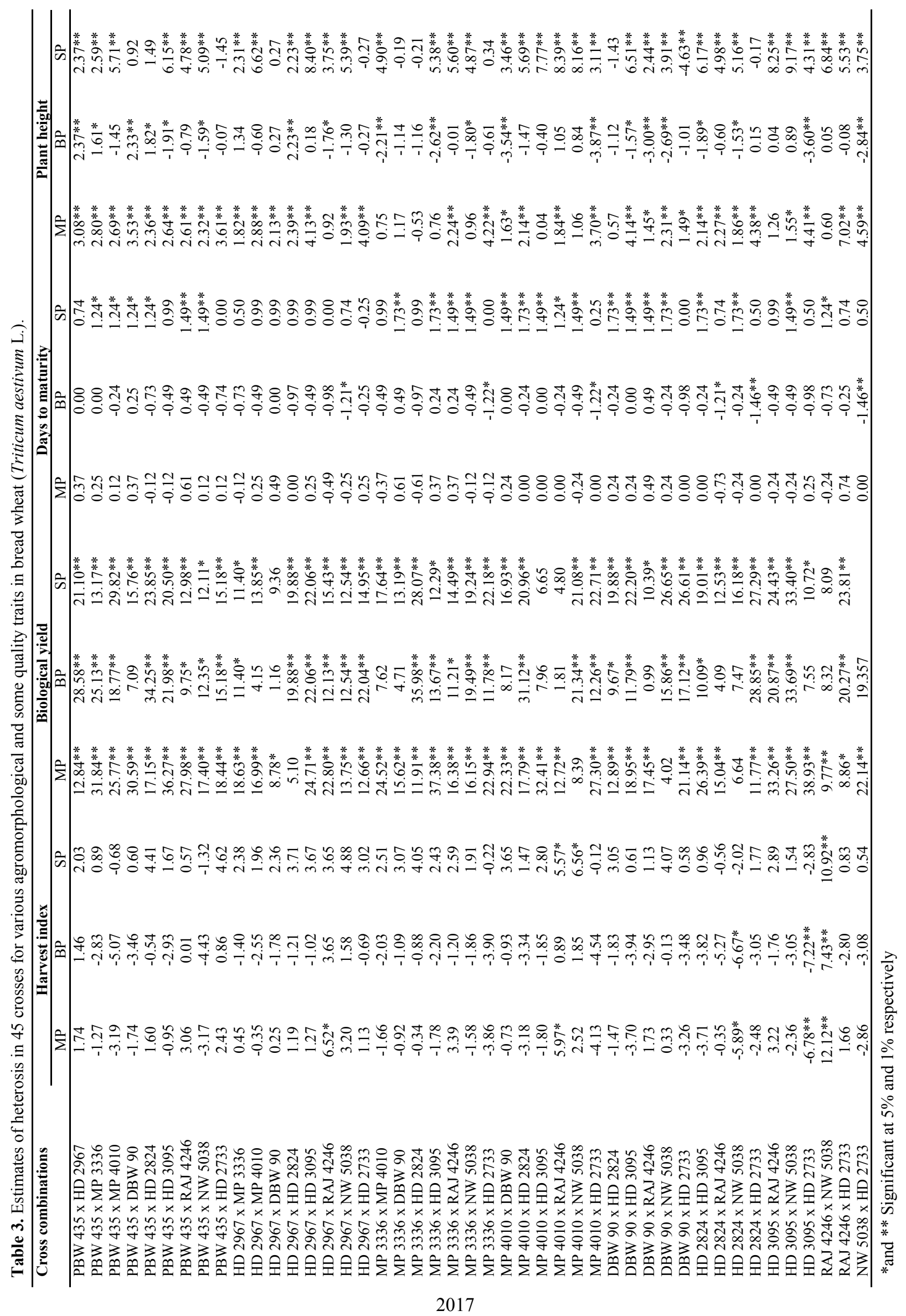




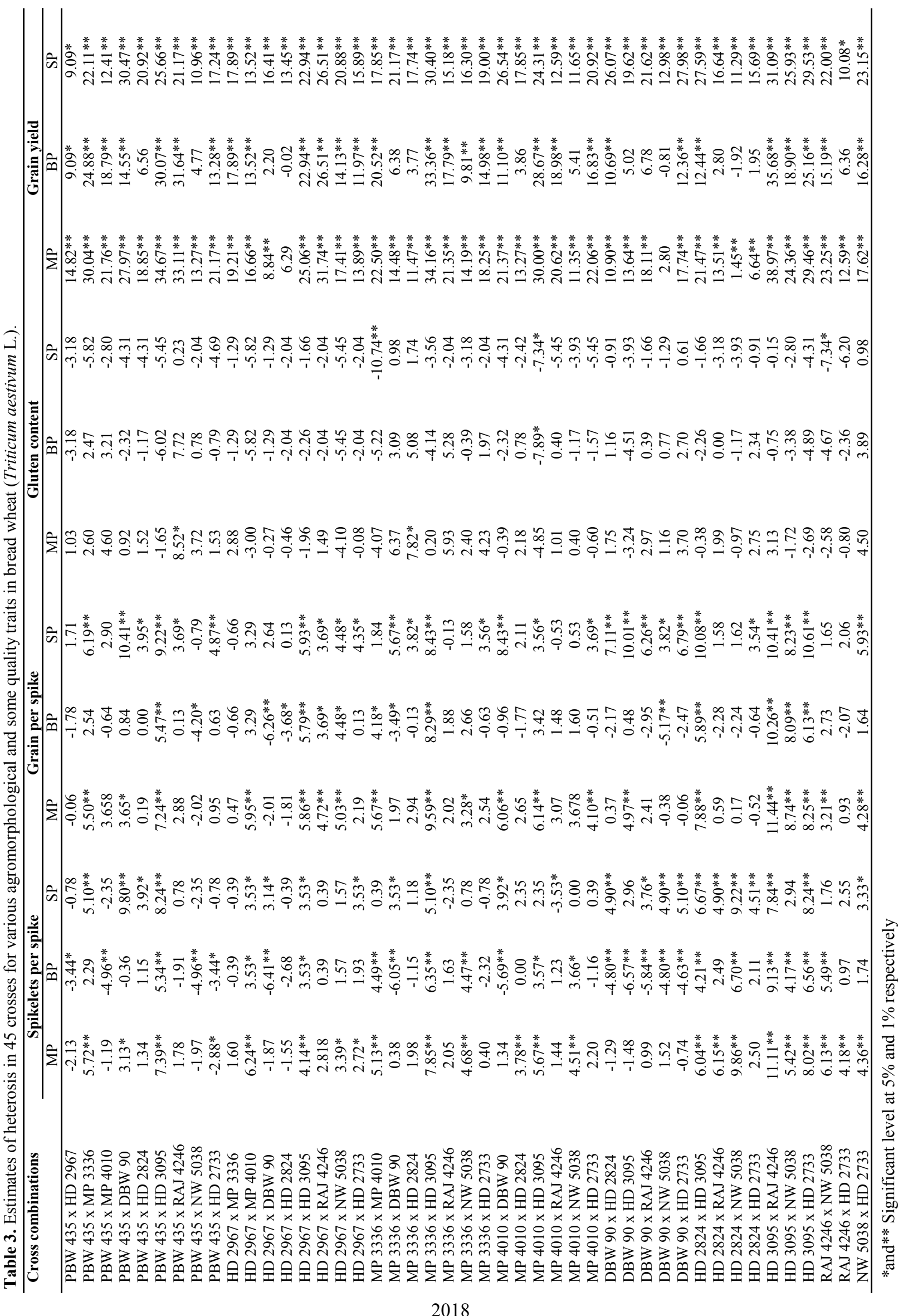


ranged from $22.14 \%$ (MP $4010 \times$ HD 3095 ) to $4.35 \%$ (HD $2824 \times$ NW 5038). The maximum heterobeltiosis $(22.14 \%)$, average heterosis $(24.03 \%)$ and standard heterosis (23.08) was showed by MP 4010 x HD 3095 . The positive and significant average heterosis range from -29.44 to 158.67 percent and heterobeltiosis value range from 1.15 to 126.37 percent was reported by Kumar and Maloo (2012) also identifying two crosses namely DBW 16 x UP 2338 and DBW 17 x UP 2338 which showed highest heterosis for productive tillers per plent in wheat. The heterobeltiotic value range from -8.97 (K $9162 \times$ K 9423) to 15.46 percent (Raj $3765 \times$ NW 1014) for productive tillers per plant was also reported by Kumar et al. (2015). The standard heterosis range from 1.97 to 113.18 percent and average heterosis range from -1.75 to 113.11 percent reported by Singh et al. (2012) and identified the cross HD 2285 × K 2021 which showed highest heterosis over mid parent and standard parent for productive tillers per plant in wheat. The importance of positive and significant heterosis for productive tillers has been reported by Singh et al. (2014), Kumar and Kerkhi (2014) and Kumar et al. (2016) in wheat crop. Higher number of productive tillers per plant is required for obtaining higher yield therefore, these crosses may prove to be the best source for higher number of productive tillers.

Positive heterosis for spike length is desirable for improving grain yield in wheat. The heterobeltiosis for spike length was ranged from $-11.23 \%$ (MP $4010 \mathrm{x}$ DBW 90) to $4.93 \%$ (PBW $435 \times$ HD 3095). The highest heterobeltiosis $(4.93 \%)$ and standard heterosis (5.41\%) was showed by PBW 435 x HD 3095 whereas highest average heterosis $(9.14 \%)$ was showed by MP 4010 x HD 3095. Singh et al. (2012) reported positive and significant average heterosis range from 19.32 to 13.19 percent and standard heterosis range from 14.81 to 33.07 percent and also identify the crosses namely $\mathrm{K}$ 9423 x K 9465 (13.19) and K 2021 x K 7903 (33.07) which showed superior heterosis over standard parent and mid parent respectively for spike length in wheat. The heterobeltiotic value range from -13.15 (K $7903 \mathrm{x}$ NW 1014) to 10.14 percent (K $9162 \times$ UP 2425) for spike length was also reported by Kumar et al. (2015). Singh et al. (2014) also reported heterobeltiosis range 27.17 to 22.29 percent and standard heterosis range from -19.79 to 16.02 percent and identify the crosses namely PBW 373 x WH 542, UP 2338 x UP 2425, UP $2425 \times$ HD 2285 and HD 2382 x UP 226 which showed highest heterosis over better parent and standard parent for spike length in wheat.

For spikelets per spike, heterobeltiosis ranged from $6.57 \%$ (DBW $90 \times$ HD 3095) to $9.13 \%$ (HD $3095 \times$ Raj 4246). The heterobeltiosis (9.13\%), average heterosis $(11.11 \%)$ and standard heterosis (9.84\%) was showed by HD 3095 x Raj 4246. Positive heterosis for spikelets per spike has been reported by Kumar and
Kerkhi (2014) and Kumar et al. (2016). The magnitude of heterobeltiosis for grains per spike ranged from $-6.26 \%$ (HD $2967 \times$ DBW 90) to $10.26 \%$ (HD 3095 x Raj 4246). The heterobeltiosis (10.26\%), average heterosis $(11.44 \%)$ and standard heterosis $(10.61 \%)$ was showed by HD 3095 x Raj 4246. The range of standard heterosis $(-24.20-28.419 \%)$ and average heterosis $(-21.60-41.26 \%)$ was reported by Singh et al. (2012); and range of heterobeltiosis $(-23.38-32.67 \%)$ and standard heterosis $(4.22-52.10 \%)$ was reported by Singh et al. (2014) for grains number per spike in wheat crop. Same pattern of heterosis for number of grains per spike in wheat crop were also reported by Kumar and Maloo (2012), Kumar and Kerkhi (2014) and Kumar et al. (2016). The number of spikelets per spike and number of grains per spike both are important yield contributing traits; therefore positive heterosis is desirable for these traits in wheat.

Heterobeltiosis for biological yield ranged from 1.16 \% (HD 2967 X DBW 90) to $35.98 \%$ (MP 3336 X HD 2824). The highest heterobeltiosis $(35.98 \%)$, average heterosis (38.93\%) and standard heterosis (33.40\%) was showed by MP 3336 x 3095, HD 3095 x HD 2733 and HD 3095 x NW 5038 respectively. The positive and significant average heterosis range from -22.74 to 105.04 percent and standard heterosis range from 20.05 to 69.02 percent was reported by Singh et al. (2012) and also identify the crosses namely HUW 234 x HD 2285 (105.04) and HUW 234 x K 9465 (69.02) which showed the superior heterosis over mid parent and standard parent respectively for biological yield in wheat. The heterobeltiotic value range from $-15.86(\mathrm{~K}$ 7903 x UNNAT HALNA) to 34.64 percent (HUW 560 $x$ NW 1076) for biological yield was also reported by Kumar et al. (2015). The heterobeltiosis range 0.64 to 65.22 percent and average heterosis range from -46.18 to 87.22 percent was reported by Kumar and Maloo (2012). The range of heterobeltiosis for harvest index varied from $-7.22 \%$ (HD $3095 \times$ HD 2733 ) to $7.43 \%$ (Raj $4246 \times$ NW 5038). The highest heterobeltiosis $(7.43 \%)$, average heterosis $(12.12 \%)$ and standard heterosis (10.92) was showed by Raj 4246 x NW 5038. The positive and significant average heterosis range from -24.08 to 73.45 percent and standard heterosis range from 17.32 to 50.23 percent was reported by Singh et al. (2012) and also identify the crosses namely K 9423 x K 7903 (73.45) and HUW 234 x K 2021 (50.23) which showed the superior heterosis over mid parent and standard parent respectively for harvest index in wheat. The heterobeltiotic value range from 28.97 (K 9162 x PBW 373) to 29.77 percent (K 7903 x UNNAT HALNA) for harvest index was also reported by Kumar et al. (2015). Similar findings for harvest index were also reported by Kumar and Kerkhi (2014) and Kumar et al. (2016). The heterobeltiosis for gluten content ranged from $-7.89 \%$ (MP $4010 \times$ HD 3095) to $7.72 \%$ (PBW 435 x Raj 4246). Maximum significant 
average heterosis $(7.82 \%)$, heterobeltiosis $(7.72 \%)$ and non significant positive standard heterosis was showed by PBW 435 x Raj 4246. Similar results for gluten content were reported by Kumar and Kerkhi (2014), Kumar et al. (2015) and Kumar et al. (2016). In general the estimates of heterosis for grain yield and gluten content were negatively correlated. However, we found some cross combinations with better significant heterotic values for both grain yield as well as gluten content, therefore these crosses may be further used in breeding programme for the exploitation of heterosis to develop wheat genotype for higher grain yield with better quality.

Heterobeltiosis for grain yield ranged from $-1.92 \%$ (HD $2824 \times$ NW 5038) to $35.68 \%$ (HD $3095 \times$ RAJ 4246). The highest heterobeltiosis (35.68\%), average heterosis $(38.97 \%)$ and standard heterosis $(31.09 \%)$ was showed by HD 3095 x RAJ 4246 which showed heterosis more than $30(\%)$. The positive and significant average heterosis range from 2.58 to 114.64 percent and standard heterosis range from 1.14 to 79.35 percent was reported by Singh et al. (2012) and also identify the crosses HUW 234 x K 9423 (114.64) and HD 2285 x K 2021 (79.35) which showed the superior heterosis over mid parent and standard parent respectively for grain yield in wheat. The heterobeltiotic value range from -9.62 (K 7903 x UP 2425) to 49.65 percent (K 9423 x NW 1014) was reported by Kumar et al. (2015) whereas heterobeltiosis range from 3.11 to 93.19 percent and average heterosis range from -40.99 to 115.65 percent was reported by Kumar and Maloo (2012) for grain yield in wheat. Same pattern of positive and significant heterosis for grain yield in wheat crop has also been reported by Singh et al. (2014) Kumar and Kerkhi (2014) and Kumar et al. (2016). At the time of selection, grain yield received maximum attention of plant breeder for selecting the desired plants or genotype. The presence of high heterosis for yield contributing components is not only for developing hybrids through exploitation of heterosis but also helps to produce transgressive segregants for developing of superior homozygous lines

\section{Conclusion}

In the present study, it may be concluded the superior performance for all the traits was not expressed in a single cross but different crosses were found to be superior for different traits. The highest heterobeltiosis $(35.68 \%, \quad 11.11 \%, \quad 11.44 \%)$, average heterosis $(38.97 \%, 9.13 \%, 10.26 \%)$ and standard heterosis $(31.09 \%, 7.84 \%, 10.41 \%)$ for grain yield, spikelets per spike and grains per spike respectively, was showed by HD 3095 x RAJ 4246 and this cross also showed significant heterosis for biological yield, flag leaf area, spike length and productive tillers. Whereas PBW 435 $x$ RAJ 4246 were common for gluten content $(8.52 \%$ and $7.72 \%$ ), grain yield (33.11\% and $33.64 \%$ ), productive tillers (16.15\% and $13.53 \%)$ and biological yield (36.27\% and $21.98 \%$ ) which showed superior average heterosis and heterobeltiosis respectively, therefore, these crosses may be exploited through heterosis breeding programme for improvement in grain yield with better quality in bread wheat genotypes and also to produce transgressive segregants for developing of superior homozygous lines in wheat.

\section{REFERENCES}

Anonymous, (2016). Progress Report of all India Coordinated Wheat and Barley Improvement Project, 1-5 pp G. P. Singh (Ed). Indian Institute of Wheat and Barley Research, Karnal

Fonseca, S. and Patterson, E.L. (1968). Hybrid vigour in seven parent diallel cross in common winter wheat (Triticum aestivum L.). Crop Sciences, 8: 85-95

Kumar Pradeep, Gyanendra Singh, Y.P. Singh and Kumar S. (2015). Identification of best heterotic cross combination from diallel crosses for grain yield and other agromorphological traits in bread wheat (Triticum aestivum L.). Electronic Journal of Plant Breeding, 6(4): 938-949

Kumar Pradeep, Ravi Kumar, Nagar, S.S., Singh, Y.P. and Abhishek D. (2016). Estimation of heterosis for grain yield and its contributing traits in bread wheat (Triticum aestivum L.). The Bioscan, 11(2): 1099-1105

Kumar, D. and Kerkhi, S.A. (2014). Heterosis studies for yield component traits and quality in spring wheat (Triticum aestivum L.). The Bioscan, 9(4): 1725-1731.

Kumar, V. and Maloo, S.R. (2012). Parental molecular diversity and its concurrence to heterosis in bread wheat (Triticum aestivum). Indian Journal of Agricultural Sciences, 82(3): 207-12

Longin, C.F.H., Mühleisen, J., Maurer, H. P., Zhang, H., Gowda, M. and Reif, J. C. (2012). Hybrid breeding in autogamous cereals. Theoretical and Applied Genetics, 125: $1087-1096$

Panse, V.G. and Sukhatme, P.V. (1967). Statistical Methods of Agricultural Workers. 2nd Endorsement, ICAR Publication, New Delhi, India, pp: 381

Singh, M.K., Sharma, P.K., Tyagi, B.S. and Singh, G. (2014). Heterosis for Yield Component Traits and Protein Content in Bread Wheat under Normal and Heatstress Environment. Cereal Research Communications, 42(1): 151-162

Singh, S.K., Chatrath, R. and Mishra, B. (2010). Perspective of hybrid wheat research: A review. Indian Journal of Agricultural Sciences, 80(12): 1013-27

Singh, H., Sharma, S.N. and Sain, R.S. (2004). Heterosis studies for yield and its components in bread wheat over environments. Hereditas, 141: 106-14

Singh, V., Krishna, R., Singh, S. and Vikram, P. (2012). Combining ability and heterosis analysis for yield traits in bread wheat (Triticum aestivum). Indian Journal of Agricultural Sciences, 82(11): 916-21 